\title{
Benefits and Harms of Wastewater in Agriculture
}

\section{Marcelo F Pompelli*}

Laboratory of Plant Physiology, Department of Botany, Federal University of Pernambuco, Recife, Pernambuco, Brazil

*Corresponding Author: Marcelo F Pompelli, Laboratory of Plant Physiology, Department of Botany, Federal University of Pernambuco, Recife, Pernambuco, Brazil. E-mail: mfpompelli@gmail.com

\section{Overview}

The distribution of water on the Earth's surface is extremely uneven. Only $3 \%$ of the water on the surface is fresh; the remaining $97 \%$ resides in the ocean. Of freshwater, $69 \%$ resides in glaciers, $30 \%$ underground and less than $1 \%$ is located in lakes, rivers and swamps. Looked the another way, only one percent of the water on the Earth's surface is usable by humans, and $99 \%$ of the usable quantity is situated underground.

Thus, there is a great variation in the rainfall between countries, being more concentrated in countries with greater vegetative coverage. Many remote areas of the world such as coastal desert areas in the Middle East and some Mediterranean are suffering from a severe shortage of drinking water. The figure 1 shows the volume of precipitated water around the world in 2012. We found
Received: May 24, 2021

Published: May 27, 2021

(C) All rights are reserved by Marcelo F Pompelli.

that in areas with hot colors the rainfall was equal to or less than $500 \mathrm{~mm}^{3}$. Thus, the largest freshwater is concentered in the Americas and Australia.

\section{How to deal with water scarcity on the planet}

The increasing water scarcity and drought was expected to occur in the context of tough competition between agribusiness and other sectors of the economy. Since water availability and accessibility are the most significant constraint factors for agricultural production, one of the alternatives to meet the challenge would be the desalination of the waters of the oceans, a technique that is still too expensive to be used on a large scale. An alternative that is increasingly gaining worldwide attention is wastewater reuse in irrigating crops.

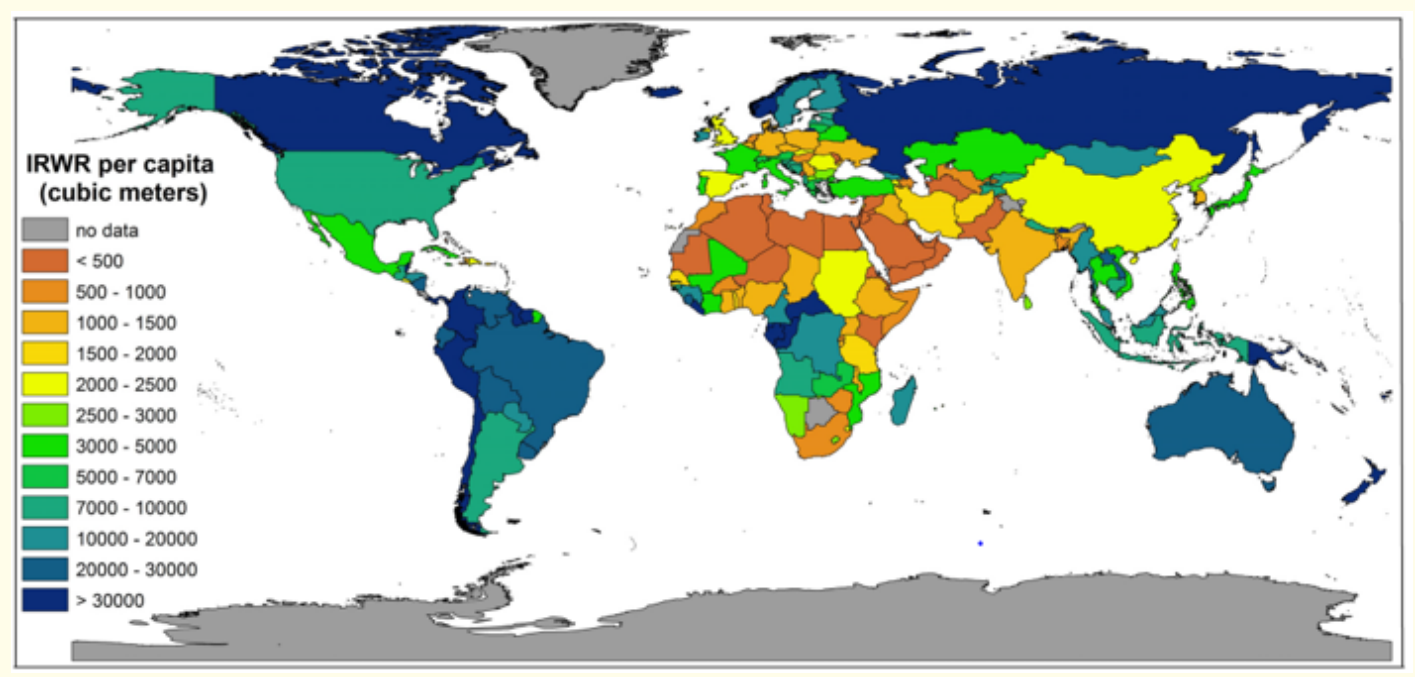

Figure 1: World map of internal renewable water resources per country in 2012 [1]. 
Benefits and harms of wastewater in agriculture

In the global context, recycled urban wastewater (RWW) in agriculture will increase in water-scarce countries soon, particularly in major cities. Irrigation with RWW has been used for complementary treatment method for wastewater, use of marginal water as an available water source for agriculture, and as a nutrient source associated with mineral fertilizer. The benefits of RWW use include conservation of freshwater reserves, less discharge of pollutants into water bodies, allows recycling of both water and nutrients and supply of nutrients to crops due to the organic matter and nutrients present in this wastewater.

In the hot areas in the map, the estimated population is about 4 billion, including the Africa continent (1,216 billion), China (1,398 billion), and India (1,366 billion). This sum is equal to 12,1-fold and 28-fold the population of the United States and Russia, respectively. Thus, the challenge of using wastewater in agriculture worldwide is becoming increasingly urgent. However, few countries have included this technique as a viable alternative for the irrigation of their plantations $[1,2]$. In this point of view, the world will begin to rethink the indiscriminate use of freshwater to prevent forecasts as expected for 2050. These areas are expected to become as arid as deserts, which will further limit food supply. In this role, Brazil deserves special attention, since it is expected for 2021 a record export of agricultural products such as soybeans, corn, cellulose and coffee, which should exceed 37,7 billion tons. Thus, if in Brazil we could replace $10 \%$ of freshwater with wastewater in agriculture, a few billion $\mathrm{mm}^{3}$ of freshwater would be spared, making Brazil the focus of attention, not for its ecological disasters, but for the gradual replacement of its freshwater.

\section{Bibliography}

1. Noemi Mancosu., et al. "Water Scarcity and Future Challenges for Food Production”. Water 7.3 (2015): 975-992.

2. María Dorta-Santos., et al. "Recycled Urban Wastewater for Irrigation of Jatropha curcas L. in Abandoned Agricultural Arid Land". Sustainability 6.2 (2014): 6902-6924.

Volume 5 Issue 6 June 2021

(C) All rights are reserved by Marcelo F Pompelli. 